\title{
77 år gammel kvinne innlagt av sosiale årsaker
}

\author{
«Innleggelse av sosiale årsaker», «akutt pleie» og «causa socialis» er begreper som ofte brukes om innleg- \\ gelser som blir antatt å være unødvendige. Men grundig vurdering av såkalt unødvendig innlagte pasienter \\ avslører ofte medisinske årsaker som både er alvorlige og kan kureres.
}

Engelsk oversettelse på www.tidsskriftet.no

> Se også side 385

\author{
Marja-Liisa Lillebø \\ marja.liisa.lillebo@helse-sunnmore.no \\ Helge Ose Velle \\ Medisinsk avdeling \\ Volda sjukehus \\ Torgeir Bruun Wyller \\ Institutt for klinisk medisin \\ Universitetet i Oslo \\ og \\ Geriatrisk avdeling \\ Oslo universitetssykehus
}

En 77 år gammel enke ble innlagt for øyeblikkelig hjelp i medisinsk avdeling i påvente av sykehjemsplass, som var blitt lovet i løpet av noen dager. Fastlegen unnskyldte seg på telefonen for at sykehuset måtte belastes med pasienten $i$ ventetiden. Hun var blitt utskrevet fra sykehuset til sykehjem knapt ett år tidligere, men hadde de siste fire månedene bodd hjemme med tilsyn av hjemmesykepleien. Den siste uken hadde hun hatt økende panikkangst med psykotisk islett og hadde ropt, grått og hyperventilert. Innleggende lege beskrev dyspné, redusert fysisk yteevne og søvnløshet. Det hadde vært opptil ti akutte tilkallinger av hjemmesykepleien per natt. De siste fire dagene forut for innleggelsen var hun blitt behandlet med zuklopentixol (Cisordinol) og diazepam. Av øvrige legemidler brukte hun atenolol, isosorbidmononitrat, lansoprazol, furosemid, acetylcystein og diazepam.

Ved innkomsten hadde hun betydelig redusert allmenntilstand, mulig dysartri, svingende bevissthetsnivå og kognitiv funksjon, og turnuslegen som tok imot henne beskrev periodevis hyperventilering. Blodtrykket var 102/84, pulsen regelmessig 110/ min og temperatur $36,6^{\circ} \mathrm{C}$. Tungen var tørr, og over basale deler av lungene var det spredte knatrelyder. Det var normale funn ved undersøkelse av hjertet og abdomen. Blodprøvene viste normale verdier for hemoglobin, betennelsesmarkører, elektrolytter, kalsium, albumin og glukose. Kreatininnivået var lett forhøyet til 106 umol/l og D-dimer til $1,0 \mathrm{mg} / \mathrm{l}$. Arteriell blodgass viste $\mathrm{pCO}_{2} 4,0$ kPa og $\mathrm{pO}_{2} 7,4 \mathrm{kPa}$. EKG viste regelmessig supraventrikulær takykardi med frekvens 110/min. Røntgen thorax viste klare lunger og sannsynligvis små mengder pleuravæske. Tentativ diagnose var innleggelse av sosiale årsaker.

«Sosial innleggelse» har ved vårt sykehus særlig blitt brukt om pasienter som mer eller mindre akutt trenger et høyere omsorgsnivå, men som blir innlagt fordi kommunen ikke kan gi tilbud om dette raskt nok. Begrepet er dårlig definert og brukes vanligvis når man antar at det ikke er medisinske grunner til innleggelsen. På morgenmøtet ble ikke pasienten diskutert fordi innleggelsen ble oppfattet som unødvendig. EKG-registreringen ble ikke ytterligere gransket.

I samtale med sønnen og en hjemmesykepleier kom det frem at det hadde gått greit hjemme inntil de siste par ukene før den aktuelle innleggelsen. Hun hadde høyresidig hemiparese etter et hjerneslag ni år i forveien, men kunne forflytte seg med stokk under tilsyn og hadde vanligvis god hukommelse. Den siste tiden hadde hun følt seg svært utrygg hjemme, og både sønnen og hjemmesykepleieren var enig om at hun måtte på institusjon.

Anamnese og klinisk observasjon tilsa at det forelå et delirium, tidligere ofte kalt «akutt forvirring» (1). Pasienten hadde en kognitiv svikt som hadde utviklet seg i løpet av et par uker, var blitt urolig, masete, desorientert og hadde til tider hallusinasjoner (ramme 1). Under visitten dagen etter innleggelsen fikk man periodevis kontakt med henne, men hun måtte vekkes flere ganger, hun hadde altså redusert oppmerksomhet. Sykepleieren rapporterte at pasienten hadde klarere stunder innimellom, altså var forløpet svingende slik det er ved delirium. Diagnosen delirium skal alltid lede til neste spørsmål: Hva utløste og hva opprettholder deliriet?

\section{Ramme 1}

Diagnostiske kriterier for delirium i henhold til ICD-10. Alle kriteriene (A-F) kreves oppfylt

A. Redusert bevissthetsnivå i form av nedsatt oppfatning av omgivelsene, med redusert evne til å fokusere og vedlikeholde oppmerksomheten, og til å endre fokus for oppmerksomheten

B. Kognitiv forstyrrelse manifesterer seg både ved

- svekket evne til umiddelbar gjenkalling og korttidshukommelse, med relativt velbevart langtidshukommelse, og

- desorientering med hensyn til tid, sted eller egne data

C. Minst én av følgende psykomotoriske forstyrrelser

- hurtig og uforutsigbart skifte fra hypo- til hyperaktivitet

- økt reaksjonstid

- økt eller nedsatt talestrøm

- tendens til å fare sammen

D. Forstyrret nattesøvn eller forstyrrelse av søvn-våkenhets-rytmen med minst en av følgende:

- søvnløshet, som i alvorlige tilfeller kan innebære totalt bortfall av søvn, med eller uten søvnighet på dagtid, eller invertert søvnrytme

- nattlig forverring av symptomene

- urolige drømmer eller mareritt, som kan fortsette som hallusinasjoner eller illusjoner etter oppvåkning

E. Akutt debut og fluktuerende forløp

F. Sykehistorie, klinisk unders $ø$ kelse eller laboratorieundersøkelser gir objektive holdepunkter for en underliggende cerebral eller systemisk sykdom (som ikke er knyttet til bruk av psykoaktive substanser) som kan antas å forårsake de kliniske manifestasjonene i kriterium $A-D$ 
Ny klinisk undersøkelse dagen etter innleggelsen ga ikke andre funn enn at hun fortsatt hadde en regelmessig takykardi og CheyneStokes' respirasjon. Vi fikk ikke frem smerter eller andre subjektive symptomer, og hun hadde ingen nytilkomne nevrologiske utfall.

Flere av legemidlene hun brukte har antikolinerge effekter og kan derfor gi kognitive bivirkninger. Zuklopentixol er i så måte mest uheldig, men kunne neppe ha forårsaket pasientens delirium ettersom dette midlet ble forordnet etter at hun var blitt forvirret. Derimot hadde zuklopentixol trolig bidratt til å forverre og vedlikeholde deliriet. Furosemid er også rapportert å ha antikolinerge effekter (2) og kan dessuten bidra til delirium via dehydrering, hypotensjon og elektrolyttforstyrrelser.

Ekkokardiografi utført dagen etter innleggelsen viste sekvele etter infarkt i septum og nedre vegg, ejeksjonsfraksjon estimert til rundt $40 \%$. Videre moderat til alvorlig mitralinsuffisiens, moderat aortainsuffisiens, samt pulmonal hypertension. Cerebral computertomografi viste et gammelt infarkt $i$ venstre hemisfære, som før.

De vanligste årsakene til delirium kunne raskt utelukkes. Hun hadde ikke tegn til infeksjon, traumer, metabolske forstyrrelser eller hjerneslag. Det var heller ikke holdepunkt for ferskt hjerteinfarkt ut fra anamnese, EKG eller ekkokardiografi, men hun hadde et sannsynlig infarktsekvele og dessuten takykardi og hjertesvikt som mulige forklaringer på delirium. Lungeembolisme var også en mulighet med hypoksi, hypokapni, pleuravæske og forhøyet D-dimer. På den tiden hadde vi ved vårt sykehus ennå ikke fått god nok CT til å utføre lungeemboliserie, og pasienter med mistanke om lungeemboli måtte sendes på tre timers reise tur/ retur til Ålesund. Dette er lite gunstig for en dårlig og delirisk pasient, så vi valgte i første omgang å forfølge andre differensialdiagnostiske muligheter.

Gjennomgang av journalen viste at hun hadde hatt gjentatte takykardianfall siden 35-årsalderen. 72 år gammel hadde hun et lite hjerteinfarkt, og etter dette hadde hun hatt gjentatte innleggelser for brystsmerter, oppfattet som angina pectoris. Knapt ett år før den aktuelle innleggelsen ble hun innlagt igjen, og da hadde man for første gang lyktes $i$ å ta EKG under takykardianfall. Registreringen viste supraventrikulær takykardi med frekvens 127/min og retrograde P-bølger ca. 100 ms etter starten av QRS-komplekset (fig 1) og således et mulig Wolff-Parkinson-Whitessyndrom (WPW). Diagnosen Wolff-ParkinsonWhites syndrom var imidlertid ikke tatt med $i$ epikrisen fra det oppholdet, den var heller ikke nevnt ved etterfølgende innleggelser, og det forelå ingen forklaring på hvorfor pasienten ikke var satt på forebyggende medikasjon.
Sykehistorien ga nå mistanke om at pasienten kunne ha anfall med supraventrikulær takykardi med økende hyppighet og varighet, som i kombinasjon med infarktsekvelet ga henne hjertesvikt, Cheyne-Stokes' respirasjon og delirium. Uhensiktsmessig behandling med psykofarmaka forverret respirasjonen, som igjen forverret angsten og sammen med midlenes antikolinerge effekter forverret deliriet. Ved fornyet inspeksjon av EKG tatt ved den aktuelle innleggelsen, ble det klart at også dette viste retrograde P-bølger.

Supraventrikulær takykardi er vanlig hos eldre og deles i flere undergrupper, hvorav atrieflimmer og -flutter er vanligst. Ved atrioventrikulærreentry-takykardi(AVRT-WolffParkinson-White syndrom) og atrioventrikulær nodal reentry-takykardi (AVNRT) har pasientene en medfødt ekstra ledningsbane mellom atriene og ventriklene. Pga. denne ekstra ledningsbanen kan det oppstå en elektrisk sirkelbevegelse mellom atrier og ventrikler og dermed takykardianfall. Ved klassisk WPWsyndrom oppstår en tidlig aktivering av deler av ventrikkelmyokard via den ekstra ledningsbunten. Dette gir opphav til en såkalt deltabølge i EKG. Ved skjult WPW-syndrom leder den ekstra ledningsbunten impulser bare en vei, fra ventrikkel til atrier, og dermed blir det ingen deltabølge utenom anfall $(3,4)$.
Vår pasient hadde hatt takykardianfall fra 35-årsalder. EKG utenom anfall var upåfallende, og det var derfor usikkert hvilken type takykardi hun hadde. EKG-registreringer under anfall (fig 1) tydet på at hun hadde anfall med skjult WPW-syndrom, selv om AVNRT ikke helt kunne utelukkes. Begge disse tilstandene kan ablasjonsbehandles med meget høy suksessrate $(>90 \%)$, eller man kan gi profylaktisk antiarytmisk behandling. Anfall kan behandles med antiarytmika, karotismassasje, andre vagale manøvre eller elektrokonvertering. Pasienten hadde relativt langsom ventrikkelfrekvens under anfall, noe som kan skyldes at hun brukte betablokker samt at ledningssystemet inkludert AV-knuten ledet langsomt.

Pasienten fikk $450 \mathrm{mg}$ amiodaron intravenøst. Sinusrytme inntrådte, men med frekvens på 38-40/min, og hun fikk blodtrykksfall og ble dårlig. Hun hadde de følgende dagene kortvarige perioder med sinusytme, og hadde $i$ disse periodene klinisk tydelig bedre allmenntilstand og kognitiv funksjon. Som rytmestabiliserende medikasjon forsøkte vi amiodaron i lavere dose etter seponering av betablokker, samt sotalol, men vi oppnådde ikke vedvarende sinusrytme. Verapamil og flekainid var uaktuelle på grunn av

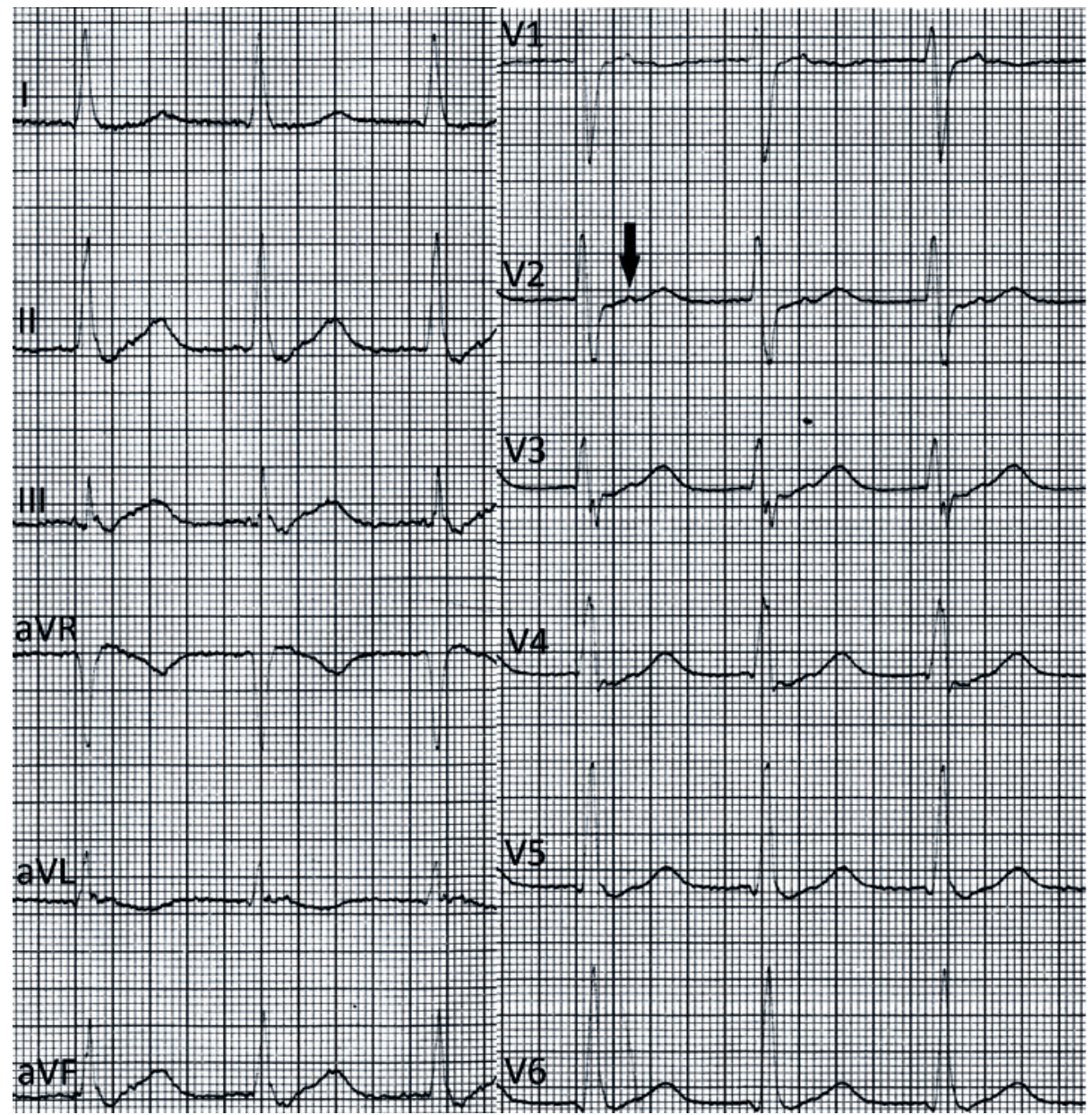

Figur 1 EKG tatt ca. et år før aktuelle innleggelse. Supraventrikulær takykardi med frekvens 127/min og med P-bølger ca. 100 ms etter start av QRS-kompleksene (pill gir mistanke om Wolff-Parkinson-Whites syndrom (WPW) 
koronarsykdom og hjertesvikt, og ablasjon ble frarådet på grunn av tidligere slag. Til slutt ble behandlingen endrett tilbake til amiodaron i kombinasjon med permanent pacemaker mot den legemiddelutløste bradykardien hun da fikk.

Så langt vi vet, hadde hun ikke nye takykardianfall, og hjertesvikten bedret seg bedømt ut fra røntgen thorax og grad av perifere ødemer. Hun klarnet opp og kunne føre en fornuftig samtale, men var $i$ dårlig fysisk allmenntilstand etter langvarig immobilisering.

En måned etter innleggelsen ble hun overflyttet til en rehabiliteringsavdeling, og etter ytterligere to uker ble hun utskrevet til sitt eget hjem med tilsyn av hjemmesykepleien. Ved kontroll etter et halvt år hadde hun ikke hatt nye episoder med angst, forvirring, dyspné eller hjertebank, og hun hadde bare ubetydelige ankelødemer. Drøyt tre år senere døde hun av en pneumoni, men med unntak av noen få ukers sykehjemsopphold rett før dødsfallet hadde hun bodd hjemme hele tiden.

\section{Diskusjon}

Delirium er svært vanlig. $15-30 \%$ av pasienter over 75 år innlagt akutt i medisinske avdelinger (1), og om lag halvparten av pasienter operert for hoftebrudd har delirium i løpet av oppholdet (5).

Delirium er fortsatt lite kjent og dermed underdiagnostisert. Pasienter med delirium er krevende pleiemessig, men også ofte diagnostisk. Det er vanskelig å få en pålitelig anamnese fra en slik pasient. Uten at diagnosen delirium blir stilt, kan grundig nok arbeid ikke bli gjort for å finne utløsende årsak, og det blir ofte sendt en snarlig sykehjemssøknad for å løse problemet. Det finnes et godt diagnostisk hjelpemiddel - Confusion Assessment Method (CAM) $(6,7)$. Dette er et enkelt skjema som med fordel kan brukes mer systematisk $i$ arbeid med gamle pasienter for sikrere å oppdage delirium. CAM oversatt til norsk er tilgjengelig på Norsk geriatrisk forenings hjemmeside (8). Bruk av CAM krever tillatelse fra rettighetshaver.

Det skilles ofte mellom risikofaktorer og utløsende faktorer for delirium. Av risikofaktorer hadde vår pasient høy alder, organisk hjernesykdom og polyfarmasi. Hennes arytmibetingede anfallsvise hjertesvikt ble oppfattet som utløsende årsak, men vi kan ikke utelukke at hun i tillegg kan ha hatt lungeemboli. Hennes arytmianfall tidligere $\mathrm{i}$ livet hadde vært kortvarige, og med et friskt myokard utviklet hun den gang ikke hjertesvikt under anfall. Anfallene var derfor ikke blitt diagnostisert tidligere, og de kunne lett forblitt udiagnostisert også denne gangen siden ventrikkelfrekvensen ikke var raskere enn 110/min og den kliniske tilstanden var dominert av delirium.

Vanlige årsaker til delirium i indremedi- sinske avdelinger er infeksjoner, akutt hjerteinfarkt, hjerneslag, legemiddelbivirkninger, elektrolyttforstyrrelser og urinretensjon. Hvilken som helst akutt sykdom kan i prinsippet utløse delirium hos en sårbar, gammel pasient, også en supraventrikulær arytmi uten spesielt rask hjerteaksjon. Men vi har ikke funnet at delirium utløst av skjult Wolff-Parkinson-Whites syndrom er beskrevet i litteraturen tidligere.

Delirium forlenger sykehusoppholdet, er ofte årsak til behov for permanent institusjonsplass og øker dødeligheten. Tilstanden kan sannsynligvis også utløse eller forverre utviklingen av demens (9). Patofysiologien er lite kartlagt, og aktuelle teorier vektlegger hypoksi, kolinerg svikt, hyperkortisolisme og proinflammatoriske cytokiner. Det er foreløpig ingen kunnskapsbasert medikamentell forebygging eller behandling. Hvis pasientene er svært urolige og agiterte, benyttes i praksis ofte haloperidol, risperidon eller klometiazol for å muliggjøre adekvat utredning og kausal behandling (10). Det er viktig med skjerming i oversiktlige, rolige omgivelser, med søvn om natten og god pleie. Men aller viktigst er det å finne frem til utløsende faktorer og fjerne dem.

Akutt syke gamle presenterer seg ofte med akutt tap av dagliglivets funksjoner som det mest iøynefallende symptomet. Dersom deres symptomer bare blir møtt med økte omsorgstiltak, er det fare for at alvorlige, men reversible tilstander blir oversett. Akutt funksjonssvikt må derfor alltid utløse en aktiv diagnostisk innsats, som også inkluderer gjennomgang av tidligere sykehistorie og kartlegging av premorbid funksjon. Vår pasient hadde alarmerende tegn på alvorlig sykdom, men til å begynne med ble innleggelsen likevel feiloppfattet som «unødvendig». «Comprehensive geriatric assessment», gjerne oversatt med bred geriatrisk vurdering, omfatter en systematisk kartlegging av fysisk funksjonsnivå, kognitiv status, emosjonell status, ernæringstilstand, komorbiditet, medikasjon og sosialt nettverk. Dette er en virksom tilnærming overfor eldre pasienter med sammensatte helseproblemer og utypisk symptomatologi (11). Takket være en slik tilnærming fikk vår pasient leve i sitt eget hjem nærmere tre år til, nesten til sin død. I dette tilfellet endte en «sosial innleggelse» med pacemakerimplantasjon og antiarytmikum. Hadde sykehjemsplass vært mer umiddelbart tilgjengelig for akuttinnleggelser, slik mange slår til lyd for, ville pasienten høyst sannsynlig ikke fått adekvat behandling. Forsøk på å unngå «unødvendige innleggelser» hos eldre pasienter kan lett føre til alvorlig tap av helse og funksjon (12).

Pasientens pårørende har gitt samtykke til at artikkelen blir publisert.

\section{Marja-Liisa Lillebø (f. 1946)}

er spesialist $\mathrm{i}$ indremedisin og i geriatri og er overlege ved Medisinsk avdeling, Volda sjukehus. Ingen oppgitte interessekonflikter.

\section{Helge Ose Velle (f. 1958)}

er spesialist i indremedisin, i allmennmedisin og i hjertesykdommer og er assisterende overlege ved Medisinsk avdeling, Volda sjukehus. Ingen oppgitte interessekonflikter.

\section{Torgeir Bruun Wyller (f. 1960)}

er spesialist i indremedisin og i geriatri, professor i geriatri ved Universitetet i Oslo og overlege ved Geriatrisk avdeling, Oslo universitetssykehus.

Oppgitte interessekonflikter: Forfatteren har mottatt forelesningshonorar fra AstraZeneca, Nycomed, Roche og Pfizer.

\section{Litteratur}

1. Inouye SK. Delirium in older persons. N Engl J Med 2006: 354: 1157-65.

2. Chew ML, Mulsant BH, Pollock BG et al. Anticholinergic activity of 107 medications commonly used by older adults. J Am Geriatr Soc 2008; 56: $1333-41$

3. Al-Khatib SM, Pritchett EL. Clinical features of Wolff-Parkinson-White syndrome. Am Heart J 1999; 138: 403-13

4. Tresch DD. Evaluation and management of cardiac arrhythmias in the elderly. Med Clin North Am 2001: 85: 527-50, xii. . xii.

5. Juliebø V, Bjøro K, Krogseth M et al. Risk factors for preoperative and postoperative delirium in elderly patients with hip fracture. J Am Geriatr Soc 2009; 57: 1354-61.

6. Inouye SK, van Dyck CH, Alessi CA et al. Clarifying confusion: the confusion assessment method. A new method for detection of delirium. Ann Intern Med 1990; 113: 941-8.

7. Wei LA, Fearing MA Sternberg EJ et al. The Confusion Assessment Method: a systematic review of current usage. J Am Geriatr Soc 2008; 56: 823-30

8. www.legeforeningen.no/geriatri

9. Krogseth M, Wyller TB, Engedal K et al. Delirium is an important predictor of incident dementia among elderly hip fracture patients. Dement Geri atr Cogn Disord 2011; 31: 63-70.

10. Ranhoff AH. Medikamentell behandling av delirium hos eldre. Tidsskr Nor Lægeforen 2004: 124 3072-4.

11. Van Craen K, Braes T, Wellens $N$ et al. The effect iveness of inpatient geriatric evaluation and management units: a systematic review and metaanalysis. J Am Geriatr Soc 2010; 58: 83-92.

12. Wyller TB. For mange eller for få innleggelser? Tidsskr Nor Legeforen 2010; 130: 1702.

Mottatt 8.3. 2011, første revisjon innsendt 22.4. 2011, godkjent 11.8. 2011. Medisinsk redaktør Trine B. Haugen. 